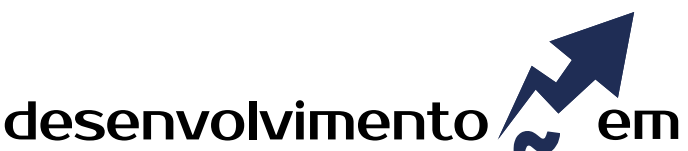 QUESTÃO
}

\section{O Discurso Desenvolvimentista sobre a Usina Hidrelétrica de Belo Monte no Contexto do Programa de Aceleração de Crescimento (PAC)}

\author{
http://dx.doi.org/10.21527/2237-6453.2021.54.28-47
}

Recebido em: $23 / 6 / 2020$

Aceito em: 27/10/2020

\section{Juliana de Oliveira Vicentini ${ }^{1}$, Carolina de Albuquerque ${ }^{2}$}

\begin{abstract}
RESUMO
O governo é uma importante fonte de informação, e uma das maneiras de o Estado disseminar conteúdos é por meio dos sites oficiais. O Programa de Aceleração do Crescimento (PAC) é de criação federal e visa a estimular o crescimento do Brasil mediante obras de infraestrutura. A Usina Hidrelétrica de Belo Monte (UHBM) é a quarta maior obra do PAC e é o principal empreendimento do eixo energético do programa. $\mathrm{O}$ objetivo é analisar criticamente os mecanismos discursivos utilizados pelo governo federal brasileiro no PAC para pôr em prática a construção e operação da Belo Monte. A materialidade de análise são os três documentos oficiais sobre o PAC e, em especial, sobre a UHBM, que estão no domínio pac.gov.br: "Sobre o PAC"; "Belo Monte: desenvolvimento com sustentabilidade"; "Belo Monte, antes e depois". A metodologia baseia-se no modelo tridimensional de análise crítica de discurso. A ideia de desenvolvimento é retomada e apresentada de forma vinculada ao planejamento estatal e à existência de um projeto social subjacente, dependente de melhoria de vida da população, com garantia de direitos por meio de políticas públicas, diferenciando desenvolvimento de crescimento. Belo Monte, no PAC, foi transformada no símbolo de desenvolvimento brasileiro, multiplicadora de investimentos e serviços, e reparadora de deficiências econômicas e sociais, perpetuando o modelo predatório de apropriação da natureza. Este discurso inalterado pode ser reapropriado para situações similares, o que disseminaria enunciados parciais que não contemplariam a complexidade social, econômica e ambiental de tais empreendimentos.
\end{abstract}

Palavras-chave: Belo Monte. Programa de Aceleração do Crescimento (PAC). Discurso. Desenvolvimento. Políticas públicas.

\section{THE DEVELOPMENTAL DISCOURSE ON BELO MONTE HYDROELECTRIC DAM} IN THE CONTEXT OF THE GROWTH ACCELERATION PROGRAM (GAP)

\begin{abstract}
The government is an important source of information. One of the ways for the State to disseminate content is through official websites. The Growth Acceleration Program (GAP) is a federal creation and aims to stimulate Brazil's growth through infrastructure works. The Belo Monte Hydroelectric Plant (UHBM) is the fourth largest project in the PAC and is the main undertaking on the program's energy axis. The construction of the dam and its current operation have generated debates until to date. This article aims is to critically analyze the discursive mechanisms used by the Brazilian federal government in the PAC to put into practice the construction and operation of the Belo Monte hydroelectric dam. The materiality of analysis are the three official documents on the PAC, especially on the UHBM that are in the pac.gov.br domain: "About the PAC"; "Belo Monte: development with sustainability"; "Belo Monte, before and after". The methodology is based on the three-dimensional model of critical discourse analysis. The idea of development is taken up and presented in a way linked to state planning and the existence of an underlying social project, dependent on improving the population's life, with guaranteed rights through public policies, differentiating growth development. Belo Monte in PAC became into the symbol of Brazilian development, a multiplier of investments and services and repair of economic and social deficiencies, perpetuating the predatory model of appropriation of nature. This unchanged discourse can be reappropriated for similar situations, which would disseminate partial statements that do not include the social, economic and environmental complexity of such enterprises.
\end{abstract}

Keywords: Belo Monte. Growth Acceleration Program (GAP). Discourse. Development. Public policy.

\footnotetext{
${ }^{1}$ Autora correspondente. Universidade de São Paulo (USP) - Escola Superior de Agricultura Luiz de Queiroz (Esalq). Avenida Pádua Dias, no 11, São Dimas. CEP 13418-900. Piracicaba/SP, Brasil. http://lattes.cnpq.br/5187082981247691. http://orcid.org/0000-0002-9031-6679. ju_vicentini@yahoo.com.br

${ }^{2}$ Universidade Federal de São Carlos - UFSCar. São Carlos/SP, Brasil.
} 
Os meios de comunicação de massa podem produzir informação de forma independente ou por intermédio de conteúdos provenientes de fontes. As fontes são "pessoas, organizações, grupos sociais ou referências; envolvidas direta ou indiretamente a fatos e eventos de quem os jornalistas obtêm informações de modo explícito ou confidencial para transmitir ao público, por meio de uma mídia" (SCHMITZ, 2011, p. 9).

O governo federal é considerado uma das principais fontes de informação para a sociedade em geral. Trata-se da fonte oficial, que representa o Estado, seja por meio de cargos, ou de instituições ou programas mantidos por ele (SCHMITZ, 2011). Este tipo de fonte "têm o grande mérito de ser reconhecível e confiável por seu status ${ }^{3}$ e prestígio, o que é importante para a mídia de massa" (HERMAN; CHOMSKY, 2003, p. 78).

Aquilo que é veiculado pelo Estado é replicado pelos mais variados meios de comunicação de massa (HERMAN; CHOMSKY, 2003). Essa disseminação de conteúdos ocorre por meio de notas, releases, coletivas de imprensa, fotos e dos sites mantidos pelo Estado, sendo estes últimos importantes fontes de propagação de conteúdo oficial por si só.

No Brasil, 79,9\% das pessoas têm acesso à internet (IBGE, 2020), o que indica ser possível que a aquisição de informações pela população não se restrinja aos meios de comunicação de massa, como TV, rádio e jornal, em razão da autonomia para o acesso a diversas plataformas, como os sites.

Os sites governamentais possuem domínio .gov e podem ser considerados prestadores de serviços de informação aos cidadãos (ALEXANDER; TATE, 2000). No Brasil, cada Ministério tem seu site próprio, bem como os diversos programas federais, como é o caso do Programa de Aceleração do Crescimento - PAC.

O Programa de Aceleração do Crescimento - PAC - é um Programa do então governo federal lançado em 2007. De acordo com a atual gestão (governo Bolsonaro) do Brasil, o PAC continua ativo e tem recebido recursos para finalizar alguns projetos em andamento, e, após a conclusão, ele será extinto. De sua criação até o presente, o objetivo do Programa, inalterado, visa a estimular o crescimento do país por meio de obras de infraestrutura nas áreas logística, urbana, administração pública e geração de energia (PAC, 2020). No segmento energético destacam-se a interligação da linha de transmissão de Tucuruí, Macapá e Manaus, a integração das usinas do Madeira com Araraquara em São Paulo e a construção de usinas hidrelétricas na Amazônia: Jirau, Santo Antônio e Belo Monte (FGV, 2020).

A Usina Hidrelétrica de Belo Monte - UHBM - é uma das maiores obras do Programa de Aceleração do Crescimento - PAC. Localizada no Estado do Pará, sua construção começou em 2011 e foi concluída em 2019. Ela é a terceira maior do seu segmento do mundo, com capacidade instalada para a geração de $11.233 \mathrm{MW}$ de energia, e quantidade média de geração de energia de 4.571 MW (NORTE ENERGIA, 2014).

Os conteúdos dos sites do governo federal - em particular o do pac.gov.br - podem ser utilizados como fonte de informação pelos meios de comunicação de massa, podem ser a fonte primária de informações para o cidadão comum e possuem amplo alcance e credibilidade. Diante disso, o objetivo deste artigo é analisar criticamente os

${ }^{3}$ Destaque dos autores. 
mecanismos discursivos utilizados pelo então governo federal brasileiro no Programa de Aceleração de Crescimento - PAC - para colocar em prática a construção e a operação da Usina Hidrelétrica de Belo Monte.

\section{BREVES CONSIDERAÇÕES SOBRE O DESENVOLVIMENTO}

O Programa de Aceleração de Crescimento - PAC - é considerado um dos "carros-chefe de uma agenda de desenvolvimento" no Brasil (LASSANCE, 2011, p. 13). O conceito de desenvolvimento foi difundido a partir de 1940. Progresso, crescimento, riqueza e bem-estar são termos amplamente associados a ele, os quais já eram discutidos no período que antecedeu o pós-guerra.

A expressão "desenvolvimento econômico", que parece tão comum, tão presente na bibliografia, na mídia, onde quer que seja, é na realidade, recente. É possível datar do segundo pós-guerra o surgimento do desenvolvimento econômico como tema. Por que isso? Evidentemente já temos, em 1945, no mínimo duzentos anos de pensamento econômico, porém, os clássicos da teoria econômica não usavam, ou usavam muito raramente a expressão "desenvolvimento econômico" - em Adam Smith aparece a ideia de material progress; Stuart Mill aborda o problema, mas não usa a expressão propriamente dita, somente com Schumpeter surge certa ênfase nessa temática, quando acentua a importância do ciclo de inovação tecnológica. Mas, na realidade, é em torno da segunda metade da década de 1940 que o uso do termo se consolida e ocorre a constituição de certo corpo teórico ou corpo doutrinário (KUGELMAS, 2007, p. 8).

Após a Segunda Guerra Mundial os países industrializados começaram a disseminar um modelo desenvolvimentista, o qual deveria ser adotado pelos países então denominados atrasados ou subdesenvolvidos (KUGELMAS, 2007). Isso deveu-se ao entendimento de que o subdesenvolvimento seria uma fase anterior ao processo desenvolvimentista (FURTADO, 2013b), e aprofundou o desejo de se construir um mundo sem guerra, desemprego, miséria, desigualdades social, política e econômica (SUNKEL; PAZ, 1988).

Por outro lado, a ideia de reprodução do modelo capitalista central sempre foi utilizada para viabilizar as pressões pelo maior uso de energia e recursos naturais não renováveis em "um sistema fechado: o planeta" (BRANDÃO, 2013, p. 14). Isto mobiliza os povos considerados periféricos a aceitarem "enormes sacrifícios para legitimar a destruição de formas de culturas arcaicas, para explicar e fazer compreender a necessidade de destruir o meio físico, para justificar formas de dependência que reforçam o caráter predatório do sistema produtivo" (FURTADO, 2013c, p. 85).

Sob o viés econômico, o desenvolvimento "é basicamente, aumento do fluxo de renda real, isto é, incremento na quantidade de bens e serviços por unidade de tempo à disposição de determinada coletividade" (FURTADO, 1961, p. 115-116). O subdesenvolvimento é estrutural, persistente e reproduzível, e é um lado da "dupla dialética" desenvolvimento-subdesenvolvimento, que se reforçam (BRANDÃO, 2013, p. 12).

Dessa forma, a reflexão volta-se para a percepção dos fatores que fazem com que países com estruturas criadas para viabilizar a expansão desenvolvimentista acumularam e acumulam "atraso", e tem um comportamento diacrônico, fundado em um elemento de intencionalidade, uma vez que as políticas econômicas intervencionistas são 
fruto da expressão de forças sociais identificáveis (FURTADO, 2013b, p. 27-28). Neste ponto, as empresas transnacionais possuem papel importante no sentido de exercerem influência assimétrica nas tomadas das decisão estratégicas, reforçando estruturas de poder mundiais (BRANDÃO, 2013).

Assim, atingir o desenvolvimento demandaria reorientar o formato de acumulação do Brasil, "ampliando a margem de arbítrio sobre nosso destino" (BRANDÃO, 2013, p. 13), o que implicaria na necessária produtividade social para legitimar um projeto nacional de desenvolvimento por meio do planejamento como técnica social ordenadora da ação estatal.

A superação do subdesenvolvimento depende de uma dimensão política, de pressões políticas da população e de um projeto social. Para Furtado (2013a, p. 53), "só haverá verdadeiro desenvolvimento - que não se deve confundir com 'crescimento econômico', no mais das vezes resultado de mera modernização das elites - ali onde existir um projeto social subjacente". A transformação do crescimento para desenvolvimento ocorre quando se prevalecem as forças que lutam pela efetiva melhoria das condições de vida da população (FURTADO, 2013a, p. 53).

No cenário brasileiro, a tentativa de superação de atraso levou à adoção de medidas governamentais de cunho desenvolvimentista, as quais são associadas majoritariamente aos governos de Getúlio Vargas e Juscelino Kubitschek (JK). Tal visão não se restringiu às gestões mencionadas, mas também perdurou após o período presidenciável de JK, estando presente nos tempos de ditadura militar.

Entre 1964 e 1990 correspondeu a uma época de forte invenção política no Brasil. A ditadura, ela mesma sinal da impossibilidade de hegemonia, promoveu uma aceleração na transformação das forças produtivas, logrando um crescimento econômico que elevou a média da expansão capitalista nos últimos cinquenta anos, quando ficou reconhecido como "milagre econômico" (OLIVEIRA, 2007, p. 16).

Oliveira (2007, p. 20) pontua que a formação do "tripé desenvolvimentista" no Brasil surgiu durante a ditadura militar, o qual foi composto por "empresas estatais-empresas privadas nacionais-empresas multinacionais".

Como foi possível observar, a postura desenvolvimentista não é uma prática nova no país, no entanto ela reapareceu fortemente a partir do governo Lula e perdurou mais intensamente até o mandato de Dilma Rousseff. Diniz (2011) adverte, porém, que ainda não há um Estado desenvolvimentista no Brasil, mas sim, uma agenda de desenvolvimento em construção:

não se delineou um modelo desenvolvimentista no sentido forte desse termo. Em outras palavras, não é possível identificar um modelo de longo prazo aglutinado de maneira consistente às distintas dimensões de uma nova estratégia de desenvolvimento, com a complexidade que alcançou o conceito contemporâneo de desenvolvimento. Além do crescimento econômico, são igualmente relevantes, nesta nova acepção, as dimensões de equidade e a expansão das liberdades substantivas das quais desfrutam os cidadãos [...] o que requer primazia da remoção das fontes de privação de liberdade, tais como: a tirania e a pobreza; a destituição social sistemática; a escassez da oferta de bens públicos essenciais nas áreas de saúde, educa- 
ção fundamental, saneamento básico, habitação e segurança pública; e, finalmente não se deve desconsiderar a dimensão da sustentabilidade, que só entrou na agenda pública recentemente (p. 17).

Para Gomide e Pires (2011, p. 25), o Brasil está "retomando políticas desenvolvimentistas por meio de um ativismo estatal observado a partir do governo Lula". Tal argumento baseia-se em uma série de políticas em andamento no país, a exemplo de medidas de cunho industrial, tecnológico, financeiro, social e infraestrutural.

\section{PROGRAMA DE ACELERAÇÃO DO CRESCIMENTO - PAC}

O Programa de Aceleração do Crescimento (PAC) foi criado em 2007 durante o segundo mandato do então presidente Lula, mas continua ativo. Trata-se de um programa que

promoveu a retomada do planejamento e execução de grandes obras de infraestrutura social, urbana, logística e energética do país, contribuindo para o seu desenvolvimento acelerado e sustentável. Pensado como um plano estratégico de resgate do planejamento e de retomada dos investimentos em setores estruturantes do país, o PAC contribuiu de maneira decisiva para o aumento da oferta de empregos e na geração de renda, e elevou o investimento público e privado em obras fundamentais (PAC, 2014a).

Em suma, o PAC visa a estimular a economia brasileira por meio de investimentos em infraestrutura, incentivando crédito, financiamento e aperfeiçoamento do setor tributário, com vistas a aumentar o investimento privado.

As obras do PAC abrangem as esferas municipal, estadual e federal. Isso significa que as duas primeiras podem submeter propostas de empreendimentos para serem financiados pelo programa federal, os quais podem ser deferidos ou não (JARDIM; SILVA, 2015, p. 64).

O PAC é um dos maiores programas já criados pelo Estado, no entanto não há um consenso sobre ele. Para Santos et al. (2010), o governo realizou uma intervenção pontual, não garantindo, assim, rupturas com o modelo neoliberal vigente, uma vez que existe uma expressiva contribuição financeira do setor privado. Segundo Sampaio Júnior (2007), o PAC não se apresenta como algo inovador, mas, sim, carregado dos mesmos parâmetros neoliberais presentes nos governos anteriores à sua criação. De acordo com Sicsú (2007), o PAC é uma oportunidade para que o Estado e o setor privado possam dialogar e atuar em conjunto em prol do desenvolvimento do país.

O PAC foi dividido em duas fases: PAC-1 e PAC-2.

O PAC-1 compreendeu o período entre 2007 e 2010, o qual visava a retomar o planejamento e execução de obras no que diz respeito à infraestrutura do país, englobando, assim, os setores: (a) logístico (rodovias, ferrovias, portos, aeroportos e hidrovias); (b) energético (geração e transmissão de energia elétrica, petróleo, gás natural e combustíveis renováveis); (c) infraestrutura social (habitação, saneamento, água, energia e transporte urbano). O PAC recebeu $\mathrm{R} \$ 503,9$ bilhões, e, deste montante, o setor que mais ganhou investimento foi o energético, sendo contemplado com $\mathrm{R} \$ 274,8$ bilhões, 0 que corresponde a $54 \%$ do investimento total (BRASIL, 2012). 
Segundo o governo federal, por meio do "mesmo pensamento estratégico, aprimorados pelos anos de experiência da fase anterior [PAC-1], mais recursos e mais parcerias com estados e municípios, para a execução de obras estruturantes que possam melhorar a qualidade de vida nas cidades brasileiras" (PAC, 2014a), o PAC-2 foi criado.

O PAC-2 foi elaborado em 2010 e iniciou em 2011 (PAC, 2014d). O então Ministério do Planejamento pontua que esta segunda fase compreende as obras relacionadas à: (a) transportes (rodovias, ferrovias, portos, hidrovias e aeroportos); (b) energia (geração e transmissão de energia elétrica, petróleo e gás natural, refino e petroquímica, fertilizantes e gás natural, revitalização da indústria naval e combustíveis renováveis); (c) cidade melhor (saneamento, prevenção em áreas de risco, mobilidade urbana e pavimentação); (d) comunidade cidadã (unidade básica de saúde, unidade de pronto-atendimento, creches, pré-escolas, quadras esportivas nas escolas, praças do esporte e da cultura); (e) minha casa minha vida (urbanização de assentamentos precários e financiamento habitacional); (f) água e luz para todos (luz e água em áreas urbanas) (PAC, 2014a). Muitos projetos dessa fase ainda não foram concluídos, portanto o PAC 2 continua em curso no Brasil em 2020.

As obras do PAC são financiadas por setores privado e público. No setor privado a captação de recurso é proveniente de "empresas, fundos de investimento do mercado financeiro, fundos de pensão e empreiteiras", que atuam em parceria com o setor público (JARDIM; SILVA, 2015, p. 64). No que diz respeito ao setor público, o Banco Nacional de Desenvolvimento Econômico e Social - BNDES - é o principal agente financiador do PAC: "assim como em 2011, em 2012 o BNDES mais uma vez foi ator principal em políticas de governo como o Plano Brasil Maior e o Programa de Aceleração do Crescimento (PAC)" (BNDES, 2012). Neste sentido, foi criado o Programa BNDES de Financiamento ao Programa de Aceleração do Crescimento, o qual visava a apoiar projetos do PAC no que se refere às frentes de infraestrutura e de operações junto aos Estados e municípios.

Segundo as informações divulgadas pelo Relatório de Investimentos do BNDES (2011, p. 84), até o ano de 2010 foram investidos R\$ 646 bilhões; entre 2011 e 2014 a estimativa é de $R \$ 955$ bilhões, e, posteriormente a 2014, são $R \$ 631,4$ bilhões, o que totaliza $R \$ 2,2$ trilhões.

Por meio de uma compilação de dados, realizada com base no Relatório de Investimentos do BNDES (2011) no PAC, foram feitos os seguintes investimentos apresentados na Tabela 1.

Tabela 1 - Participação do BNDES no PAC: 2007-2011

\begin{tabular}{c|c|c|c}
\hline SETOR & PROJETOS & $\begin{array}{c}\text { INVESTIMENTO } \\
\text { GLOBAL }\end{array}$ & $\begin{array}{c}\text { INVESTIMENTO } \\
\text { BNDES }\end{array}$ \\
\hline Energético & $\begin{array}{c}310 \text { (geração, transmissão, petró- } \\
\text { leo e gás) }\end{array}$ & $\mathrm{R} \$ 259$ milhões & $\mathrm{R} \$ 137.240$ milhões \\
\hline Logístico & $\begin{array}{c}94 \text { (rodovias, ferrovias e marinha } \\
\text { mercante) }\end{array}$ & $\mathrm{R} \$ 50$ milhões & $\mathrm{R} \$ 31.314$ milhões \\
\hline $\begin{array}{c}\text { Social/urbano } \\
\begin{array}{c}\text { Administração } \\
\text { pública }\end{array}\end{array}$ & $\begin{array}{c}\text { 14 (criação do sistema de escritu- } \\
\text { ração digital) }\end{array}$ & $\mathrm{R} \$ 18$ milhões & $\mathrm{R} \$ 10.667$ milhões \\
\hline TOTAL & 503 & $\mathrm{R} \$ 196$ milhões & $\mathrm{R} \$ 166$ milhões \\
\hline
\end{tabular}

Fonte: As autoras a partir do Relatório Anual BNDES (2011). 
Entre os quatro principais setores de atuação do PAC, o que mais possui projetos e investimento financeiro é o energético. Embora este eixo seja composto por diversas frentes (conforme citado anteriormente), as principais obras deste segmento dizem respeito à geração de energia elétrica.

A matriz energética nacional é marcada majoritariamente pela geração de eletricidade proveniente de fontes hídricas. A estratégia de construir hidrelétricas para gerar energia teve início na década de 30, durante o governo Vargas, por meio do ideal "Brasil Grande", o qual executou grandes projetos relacionados à exploração de recursos naturais, a exemplo da usina hidrelétrica de Itaipu (KHAGRAM, 2004).

A região Norte do país abriga cerca de $43 \%$ do potencial energético do Brasil (PNE, 2007). Este dado, somado à exploração de minérios e à agropecuária, por exemplo, aumentou consideravelmente a demanda energética da região, o que justifica, em parte, a construção das primeiras grandes hidrelétricas na Amazônia nos anos 1970. Pereira (2013) destaca que a construção de tais empreendimentos na região remonta o Segundo Plano Nacional de Desenvolvimento (II PND) e o PNEE 1987-2010. Isso totalizaria a construção de 79 barragens na Amazônia para aumentar o aproveitamento da capacidade hidrelétrica da região (FEARNSIDE, 2006).

A maior e mais polêmica obra na Amazônia é a usina hidrelétrica de Belo Monte, um dos principais empreendimentos do PAC.

\section{USINA HIDRELÉTRICA DE BELO MONTE - UHBM}

A Amazônia tem sido o alvo de diversos projetos voltados à construção de usinas hidrelétricas. Na bacia do Rio Tapajós, por exemplo, estima-se a concretização de 43 empreendimentos dessa natureza (GREENPEACE, 2018). Diante disso, é possível inferir que o objetivo é transformar a região em um grande complexo energético.

A usina hidrelétrica de Belo Monte localiza-se no Estado do Pará, na bacia hidrográfica do Rio Xingu, na Amazônia brasileira. O empreendimento compreende a região das cidades de Altamira, Vitória do Xingu, Senador José Porfírio e Anapu, na área conhecida como Volta Grande do Xingu (Figura 1).

Figura 1 - Localização da Usina Hidrelétrica de Belo Monte

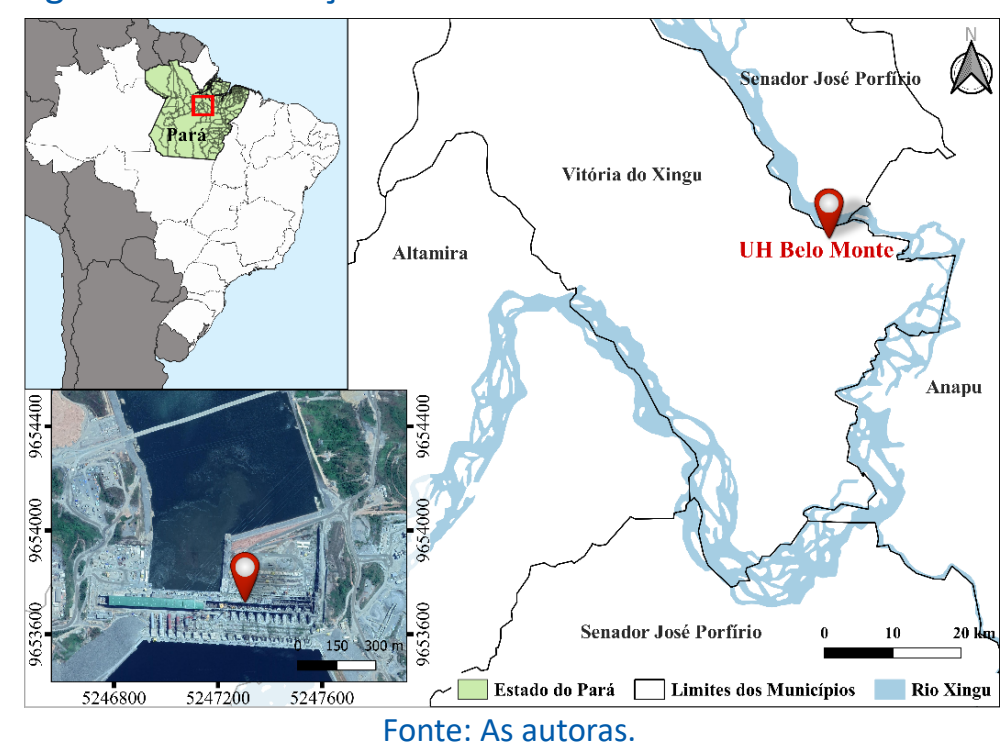


Os debates acerca da construção do empreendimento não são fenômenos recentes. Eles iniciaram entre os anos de 1970 e 1980, na ocasião dos Estudos de Inventário Hidrelétrico da Bacia Hidrográfica do Rio Xingu (MXVPS, 2010; MME, 2011). A usina fazia parte do plano de integração nacional da Amazônia. Em 1989, no entanto, como resultado do 1 을 Encontro dos Indígenas do Xingu, o projeto da hidrelétrica foi rejeitado (BERMANN, 2012).

A usina hidrelétrica de Belo Monte reapareceu como pauta durante o governo de Fernando Henrique Cardoso com o Avança Brasil (2000-2003), caracterizado como “(...) um programa massivo de construção de infraestrutura e outras atividades" (FEARNSIDE, 2002, p. 735). Mais uma vez as discussões ficaram em âmbito teórico e o empreendimento não foi concretizado. Na gestão de Luís Inácio Lula da Silva a usina voltou à cena por meio do Programa de Aceleração do Crescimento - PAC.

A UHBM iniciou suas operações em 2015; "é o principal projeto energético do PAC e uma das grandes prioridades do programa por garantir energia limpa e renovável a um custo bem abaixo das alternativas existentes. O investimento previsto na usina é de $\mathrm{R} \$ 25,8$ bilhões" (PAC, 2014b).

A usina de Belo Monte é uma obra polêmica. Desde o planejamento, construção e operação, este empreendimento tem sido marcado por inúmeros debates e conflitos. A obra mobilizou diversos atores sociais nacionais e internacionais: (1) desfavoráveis à usina; e (2) a favor dela.

(1) O grupo que se posiciona contra a hidrelétrica pauta-se nas consequências socioambientais de Belo Monte (HOCHSTETLER, 2011; FEARNSIDE, 2006). Este é composto pelo Movimento dos Atingidos por Barragem (MAB); Movimento pelo Desenvolvimento da Rodovia Transamazônica pelo Xingu (MPDTX); International Rivers Network (IRN); Living Rivers Coalition; Instituto Socioambiental (ISA); Friends of the Earth-Brazilian Amazônia (FOE-AP); Greenpeace; Conservation International (Cl); Movimento Xingu Vivo para Sempre (MXVPS); Movimento das Mulheres Trabalhadoras de Altamira do Campo e da Cidade (MMTACC); ativistas; líderes comunitários; indígenas; personalidades; cientistas.

(2) Os agentes a favor da usina argumentam que se trata de uma obra de interesse estratégico para o país por permitir a manutenção do crescimento econômico brasileiro (HOCHSTETLER, 2011; FEARNSIDE, 2006, 2015), o qual é composto pelo Conselho Nacional de Política Energética (CNPE); Ministério de Minas e Energia (MME); Agência Nacional de Energia Elétrica (ANEEL); Centrais Elétricas Brasileiras (Eletrobras); políticos; empresários.

Ao longo da história de Belo Monte, sua construção nunca atingiu um consenso. Ainda assim, a realização do empreendimento foi concretizada e, hoje, a usina está em operação no Pará.

A materialidade discursiva do PAC continua no ar por meio do site governamental. Isso significa que ela pode ser utilizada como referência para projetar novas obras com o mesmo apelo linguístico. Diante disto, é importante analisar criticamente os discursos sobre a usina de Belo Monte nos enunciados oficiais do site PAC. 


\section{MATERIAL E MÉTODO}

O corpus é composto pelos materiais disponibilizados pelo governo federal sobre o PAC no próprio site do programa, com ênfase no eixo energético, no qual Belo Monte é a principal obra: "Sobre o PAC"; "Belo Monte: desenvolvimento com sustentabilidade"; "Belo Monte: antes e depois".

O referencial teórico-metodológico baseia-se na análise crítica de discurso. Ela compreende a linguagem como um recurso "na constituição e na transmissão de conhecimento, na organização das instituições sociais e no exercício do poder" (PEDROSA, 2008 , p. 119). Segundo Fairclough (2001, p. 91), “o discurso é uma prática, não apenas de representação do mundo, mas de significação do mundo, constituindo e construindo o mundo em significado".

O autor propõe um modelo tridimensional de análise, no qual o discurso é passível ser analisado como: (1) texto, (2) prática discursiva e (3) prática social (Figura 2).

Figura 2 - Modelo tridimensional de Análise Crítica do Discurso

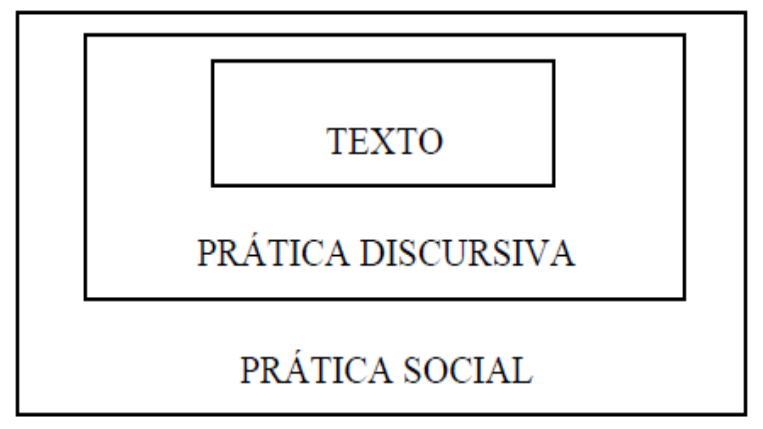

Fonte: As autoras, baseadas em Fairclough (2001, 2008).

1 - Análise textual: contempla a análise do vocabulário, gramática, coesão e estrutura textual, a fim de verificar sua forma e seu significado. Para o autor, o texto pode ser escrito ou falado, ou contemplar ambas as modalidades simultaneamente, como nos casos de programas televisivos e vídeos. 2 - Prática discursiva: abrange os processos de produção, distribuição e consumo textual, que são processos sociais relacionados a ambientes políticos, econômicos e instituições particulares. Além disso, a força dos enunciados, a coerência dos textos, a intertextualidade e a interdiscursividade também podem ser examinados. 3 - Prática social: é um modo de ação em que o discurso não apenas representa o mundo, mas também o significa. As orientações da prática social, que podem ser econômicas, políticas, ideológicas e culturais, são analisadas para investigar como a hegemonia colabora tanto com a desarticulação quanto com a rearticulação de complexos ideológicos.

Embora seja possível priorizar uma das três dimensões, é aconselhável que a análise textual seja conduzida em conjunto com as práticas discursiva e social: ao analisar textos sempre examinam-se simultaneamente questões de forma e questões de significado (FAIRCLOUGH, 2001, p. 102). O autor destaca que o modelo de análise deve ser adaptado conforme as necessidades do analista. 


\section{O DISCURSO FEDERAL SOBRE BELO MONTE NO PAC}

O Programa de Aceleração do Crescimento - PAC - foi prioridade do governo federal nas gestões de Lula e Dilma e continua ativo na atual gestão de Bolsonaro. 0 programa tornou-se aquilo que Castoriadis (1987) considera uma espécie de slogan de desenvolvimento, ou seja, um recurso utilizado pelas nações para exaltar seu (aparente) compromisso com o desenvolvimento (CASTORIADIS, 1987). O nome do Programa é composto pelo vocábulo "crescimento", mas é utilizado como sinônimo de "desenvolvimento", como pode ser notado nas primeiras linhas do discurso introdutório sobre o PAC no site governamental: "Está em curso no Brasil um modelo de desenvolvimento econômico e social4" (PAC, 2014a).

Crescimento não é sinônimo de desenvolvimento. O primeiro está atrelado ao aumento do Produto Interno Bruto (PIB). O segundo relaciona-se ao bem-estar geral da população. Nesse sentido, a ideia de desenvolvimento econômico é um mito que desvia a atenção das necessidades fundamentais da população e das perspectivas que decorrem do avanço da tecnologia, para focar em "objetivos abstratos como: investimentos, exportações e crescimento" (FURTADO, 2013c, p. 85).

O mero crescimento ou o mau desenvolvimento está a serviço da manutenção do status quo, ou seja, ele tende a proteger os interesses existentes. Já o verdadeiro desenvolvimento permite romper com as estruturas determinantes do subdesenvolvimento e do acúmulo de atraso, sendo o planejamento estatal decisivo neste cenário (FURTADO, 2013b; BRANDÃO, 2013).

Uma das bases do discurso desenvolvimentista reside em investimentos e realização de grandes empreendimentos, os quais podem ser exemplificados por meio dos discursos do PAC:

"A hidrelétrica [Belo Monte], considerada uma das obras mais estratégicas do PAC, começa enfim a sair do papel" (PAC, 2014c).

"[O PAC] Combina crescimento da economia com distribuição de renda e proporciona a diminuição da pobreza e a inclusão de milhões de brasileiros e brasileiras no mercado formal de trabalho" (PAC, 2014a).

"[O PAC] Garantiu a continuidade do consumo de bens e serviços, mantendo ativa a economia" (PAC, 2014a).

Dessa maneira, as obras relacionadas à infraestrutura são projetadas como estimuladoras e responsáveis pelo crescimento/desenvolvimento e são geradoras de receitas. Neste sentido, o PAC pode ser entendido como a solução de todos os problemas existentes (CABRERA, 1996) no Brasil.

"Pensado como um plano estratégico de resgate do planejamento e de retomada dos investimentos em setores estruturantes do país, o PAC contribuiu de maneira decisiva para o aumento da oferta de empregos e na geração de renda, e elevou $o$ investimento público e privado em obras fundamentais" (PAC, 2014a).

\footnotetext{
${ }^{4}$ As autoras do presente artigo optaram pelo uso do itálico para destacar os trechos analisados extraídos dos documentos governamentais.
} 
"O desafio da política econômica do governo federal é aproveitar o momento histórico favorável do país e estimular o crescimento do PIB e do emprego, intensificando ainda mais a inclusão social e a melhora na distribuição de renda" (PAC, 2014a).

Há uma reiteração discursiva a respeito do significado de desenvolvimento para o governo federal: investimento, emprego e renda. A agenda do PAC-1 é composta pelos eixos de energia, logística e infraestrutura, ou seja, não há, de fato, uma preocupação de cunho essencialmente social, focando-se, novamente, em objetivos abstratos.

O avanço social dos países em desenvolvimento não está relacionado a uma evolução automática, decorrente apenas de aumento de PIB, mas da capacidade de a sociedade exercer pressões políticas, definindo seu perfil social, o que não trata exclusivamente da valoração de seu consumo e de sua acumulação (FURTADO, 2013d, p. 53).

É necessário dar importância aos parâmetros não econômicos dos modelos macroeconômicos, principalmente em sistemas heterogêneos, como o das economias subdesenvolvidas. Nelas há uma minoria modernizada que se apropria do excedente e pretende acompanhar o estilo de vida dos países que lideram o progresso. Dessa maneira, a industrialização dá-se de forma simultânea à concentração da renda, com crescentes desigualdades sociais, e descreve a dependência cultural (FURTADO, 2013b).

No PAC-2 há o eixo denominado "comunidade cidadã", englobando obras nas áreas de saúde e construção de creches, pré-escolas e praças de cultura. Ainda assim, esses segmentos não são considerados disparadores daquilo que o governo rotula como desenvolvimento, que depende de avanços sociais vinculados ao crescimento econômico.

Como já mencionado, a UHBM é "considerada uma das obras mais estratégicas do PAC" (PAC, 2014c), portanto pode ser considerada o "símbolo de um modelo de desenvolvimento" (RAMOS; ALVES, 2018, p. 175). Afinal de contas, porém, o que é esse empreendimento? Os documentos oficiais do PAC têm a resposta:

[Belo Monte] "é a quarta maior obra do PAC e, apesar de entrar em operação em 2015, só será concluída em 2019, ficando atrás apenas de Itaipu e Três Gargantas, na China, entre as maiores do mundo. Com capacidade de gerar $11.223 \mathrm{MW}$ de energia elétrica (média de $4.571 \mathrm{MW}$ ), Belo Monte é o principal projeto energético do PAC e uma das grandes prioridades do programa por garantir energia limpa e renovável a um custo bem abaixo das alternativas existentes. $O$ investimento previsto na usina é de $R S$ 25,8 bilhões" (PAC, 2014c).

O discurso governamental faz uso do superlativo. Este recurso linguístico é um tipo de gradação empregado para exprimir algo com intensidade (MARTIN; WHITE, 2005). De acordo com Houaiss (2009, p. 1791), o superlativo "1 exprime uma qualidade num grau muito elevado ou mais elevado 2 que tem caráter de excelência <elogio s.> 3 elevado ao mais alto ponto ou grau <o iate era a expressão s. de sua riqueza > s.m [...]". No presente estudo, Belo Monte é a "quarta maior" obra do PAC, e na categoria usina hidrelétrica está entre "as maiores do mundo".

Os temas relacionados à Amazônia são costumeiramente superlativizados; assim, ela é considerada "uma terra de superlativos" (BURSZTYN; ASSUNÇÃO, 2004, p. 295). Como pode ser observado, seguindo esta tendência, no PAC a UHBM é construída discursivamente como um empreendimento de superlativos. 
Belo Monte é a principal obra energética do PAC. Como já apontado, trata-se de um programa com cunho desenvolvimentista. Dentro desse contexto, a UHBM é transformada em um sinônimo de desenvolvimento. Neste caso, todavia, o vocábulo desenvolvimento foi utilizado como uma espécie de "slogan" e de "ideologia oficial", o qual é visto como reconstrutor econômico de nações, como o solucionador de problemas humanos, como um processo inevitável na sociedade e intrínseco ao objetivo humano (CASTORIADIS, 1987).

Tal modelo, no entanto, preocupa-se com ele próprio. Ele desconsidera as consequências humanas, mostrando-se incapaz de assegurar o crescimento de fato, resultando em uma distribuição desigual dos frutos do crescimento, acarretando uma série de danos ambientais e gerando a necessidade de criação de setores responsáveis por cuidar da qualidade de vida (CASTORIADIS, 1987).

Neste contexto, é importante destacar que o planejamento e a realização de grandes obras são acompanhados por grandes inquietações. Embora tenha havido algumas audiências públicas para consultar a população - pois isto é uma exigência do protocolo do Estudo de Impacto Ambiental - acerca da efetivação do empreendimento em questão, a construção de usinas hidrelétricas (em particular na Amazônia) tem sido marcada historicamente por protestos, denúncias, descasos, danos ambientais, culturais e sociais (FEARNSIDE, 2006, 2015) que não foram superados. Ainda assim, tais acontecimentos são postos em segundo plano.

Embora o vocábulo desenvolvimento seja utilizado como sinônimo de crescimento, conforme já abordado, cada um deles possui suas particularidades. A lacuna de crescimento econômico, contudo, é o principal obstáculo do desenvolvimento, e para superá-lo é preciso investir em: capital estrangeiro, criação de polos de desenvolvimento, importação e instalação de máquinas, assistência técnica e qualificação profissional (CASTORIADIS, 1987). Nesta mesma linha de pensamento, Cabrera (1996, p. XIII) completa que a sociedade está presa à ideia de desenvolvimento "como se fosse a única esperança de salvação", e, por meio do discurso do Estado no PAC, a UHBM foi considerada a única alternativa para o desenvolvimento da região onde ela foi construída:

"No caso da usina hidrelétrica Belo Monte, que será construída no rio Xingu na região de Altamira (PA), está sendo possível dar melhores condições sociais, econômicas e ambientais aos milhares de habitantes dos 10 municípios que estão direta e indiretamente na área de influência da obra. Para isso, além das contrapartidas previstas no licenciamento ambiental, foi elaborado o Plano de Desenvolvimento Regional Sustentável (PDRS) do Xingu, que conta com $R \$$ 2,5 bilhões de recursos - $R \$ 2$ bilhões do governo federal e R\$ 500 milhões do consórcio Norte Energia S.A. (Nesa), responsável pelo empreendimento. Estes recursos serão utilizados em ações como ampliação e melhorias de escolas, unidades de saúde, urbanização, projetos de capacitação da população, fomento industrial e comercial e construção de moradias, entre outras ações fundamentais para atender o aumento populacional na região e compensar e minimizar outros impactos trazidos pela chegada da usina" (PAC, 2014b).

Boa parte das políticas públicas para a efetivação de direitos sociais, como saúde e educação, que deveriam ter sido oferecidas pelo governo ao longo de toda a história daquela região, foram terceirizadas para o consórcio responsável pelo empreendimen- 
to: Norte Energia. Assim, a UHBM é considerada a impulsionadora e salvadora da estagnação econômica local, sendo simultaneamente responsável pela suposta prosperidade da população.

A problemática direciona-se para o fato de que direitos como saúde e educação se tratam de direitos denominados sociais e encontram fundamento no princípio da igualdade material, implicando na necessidade de políticas públicas direcionadas à alocação de recursos para a redução das desigualdades sociais (DUARTE, 2013). Assim, não basta que o Estado dê liberdade para o cidadão se autodeterminar ou que firme contratos para ações da iniciativa privada, como com a Norte Energia, para a sua efetividade, sendo imprescindível que atue para que a fruição desses direitos aconteça efetivamente.

Esperar que a iniciativa privada ocupe essas áreas em Belo Monte é insuficiente, pois, mesmo havendo essa ocupação, o acesso das populações vulneráveis depende da sua atuação ao menos fiscalizatória e de manutenção de atividades pelo Estado ao longo do tempo. Para além da construção de escolas, creches, unidades de saúde etc., portanto, é necessária a disponibilização de recursos humanos e financeiros contínuos para que a existência de infraestrutura se exteriorize em efetivo acesso a direitos sociais.

O desenho e a concretização de políticas públicas pelo Legislativo e Executivo acontecem com a criação de leis, destinação de dotação orçamentária e de uma estrutura que permita a viabilidade da atividade pretendida, que, por ser instituída de forma progressiva (BONAVIDES, 2010), depende de acompanhamento paulatino. Dessa forma, sabe-se que não será de imediato que todas as necessidades de Belo Monte serão sanadas, mas deve haver uma programação de execução confeccionada pelo Estado, passível de acompanhamento pela população interessada.

Isso porque a análise das políticas públicas envolve tanto a ação governamental quanto o processo de decisão sobre a política pública, conceituado como um programa "de ação governamental que resulta de um conjunto de processos disciplinados pelo Direito voltados à realização de fins socialmente relevantes e juridicamente determinados" (BUCCl, 2006, p. 39). Nesse sentido, a política pública possui um ciclo composto das seguintes etapas: formação e planejamento, efetivação, avaliação, fiscalização e controle (BUCCl, 2006). Assim, atividades direcionadas a ações específicas, dentro de prazos determinados, apesar de favorecerem as estruturas para a consecução das políticas públicas, devem estar vinculadas a essas outras etapas, pois a política pública deve ser prolongada no tempo e deve ser paulatinamente ampliada, sendo vedado o retrocesso, independentemente do aumento da população que a utiliza.

Esse pressuposto dificulta que tais ações sejam protagonizadas pelo setor privado - apesar de terem potencial para serem consideradas agentes facilitadores e financiadores da execução de tais políticas (SILVA, 2009). Essa dificuldade reside justamente no fato de que as políticas públicas não podem ser interrompidas, ou seja, vinculadas a contratos, por exemplo, ou respeitadas como condicionantes por prazo determinado como no caso de Belo Monte. 
Além disso, a não intervenção em políticas públicas, ou seja, a permissão para que o Estado não a efetive ou deixe de acompanhá-la e custeá-la, está atrelada exclusivamente a fundamentos de cunho constitucional (SILVA, 2009), portanto deve haver uma permissão da constituição para eventual omissão estatal, o que não ocorre no caso em concreto.

A proteção jurídica e a obrigatoriedade de consecução das ações vinculadas ao PAC, pela iniciativa privada, são pouco efetivas se as autoridades políticas não estão empenhadas em seu cumprimento e fiscalização por meio de planejamento amplo. Assim, o prejuízo à política pública dá-se na omissão governamental, uma vez que, apesar de verificado o planejamento para a realização de obras de infraestrutura para a efetividade dos direitos sociais, não estão descritas as ações de efetivação dos benefícios, como recursos para contratação de pessoal e insumos para a efetividade da política pública. Assim, a permanência e a continuidade da política acabam prejudicadas, o que pode indicar uma personalização do poder (ROMANO, 2008) e não afasta o fato de que o direito à prestação obriga o Estado, e não a iniciativa privada, a respeitar, proteger e executar os Direitos Sociais (DUARTE, 2013).

A privatização dos direitos sociais afasta a participação popular nas tomadas de decisão, mesmo que por intermédio de representação política, e o enfraquecimento das instituições da sociedade civil pode implicar o agravamento dos aspectos antissociais do subdesenvolvimento, mesmo com a intensificação do crescimento econômico (FURTADO, 2013b).

Exemplos da dificuldade de participação popular na construção da UHBM são importantes e podem ser observados em vários pontos da sua história. Em 2001, o Ministério Público Federal (MPF) impetrou Ação Civil Pública para suspender o Estudo de Impacto Ambiental (EIA) da Usina por vários motivos, inclusive pela falta de consulta aos indígenas. Diante disto, vários grupos da sociedade civil se articularam, reunindo 113 organizações sociais para a elaboração do documento "SOS Xingu: Um chamamento ao bom senso sobre o represamento de rios na Amazônia". Em 2004, o Conselho de Defesa dos Direitos da Pessoa Humana (CDDPH), em razão de denúncias de violações de direitos, criou uma Comissão Especial (CE). Em 2009, os ElAs foram entregues sem a inclusão das considerações dos indígenas e quatro audiências públicas aconteceram abordando os seguintes problemas: as audiências eram agendadas em localidade distante dos grupos atingidos; o tempo direcionado a manifestações das populações era curto; a linguagem utilizada era inapropriada, sendo recomendado pelo MPF a realização de mais 13 audiências e a escrita de mais 1 carta das comunidades denominada "Comunicado dos Povos Indígenas sobre a usina de Belo Monte". Em 2010, a licença prévia (LP) foi concedida, com 40 condicionantes, sendo apontadas pelo MPF irregularidades, como falta de estudo aprofundado sobre as questões indígenas e desconsideração das audiências públicas. Em 2011 ocorreram manifestações contra a usina e a concessão de uma licença parcial, inexistente na legislação brasileira, mesmo sem que as condicionantes pré-fixadas tivessem sido atendidas. As obras começaram em 2013, e no final de 2014 70\% delas estavam concluídas sem a expedição de Licença de Operação (LO). Em 2015, o MPF lançou relatório apontando a remoção compulsória dos ribeirinhos com riscos físicos e culturais, coação para aceitar a indenização e o enchimento da represa foi autorizado (FAINGUELERNT, 2016). 
No caso da UHBM, até o momento (2020) foram impetradas 27 ações civis públicas pelo Ministério Público Federal, e em 4 ocasiões houve a suspensão das obras (MINISTÉRIO PÚBLICO FEDERAL, 2020). Além disso, a Comissão Interamericana de Direitos Humanos, em caso apresentado pelas comunidades tradicionais locais, determinou cautelarmente a interrupção da construção da Usina até a garantia dos direitos das comunidades, inclusive com consulta às populações indígenas. Em razão de pressão estatal, a Comissão Interamericana afastou a paralização da obra, mas manteve a necessidade de consulta (SCABIN; CRUZ; HOJAIJ, 2015).

A "desarticulação entre a agenda local e a do empreendimento" traz a sensação de que as decisões já foram tomadas antes da audiência, ou reunião, havendo um espaço de negociação diminuto, mas com efetividade de seu efeito simbólico. Vários fatores favorecem o problema: curto cronograma das obras, confusão sobre os papéis das empresas e do governo em relação aos investimentos nas políticas públicas locais e obrigações de as empresas fomentarem ou criarem serviços educacionais ou de saúde, que são obrigações constitucionais do Estado (FGV, 2013).

Na realidade, "existe uma repetição de um mesmo padrão de política pública (na construção de grandes hidrelétricas na região amazônica), que desrespeita a legislação ambiental brasileira e os direitos das populações tradicionais atingidas pela obra" (FAINGUELERNT, 2016, p. 261). Para além, portanto, da questão do uso de recursos financeiros privados ou públicos, está o debate sobre a gestão do desenvolvimento no país, sendo os impactos sociais subdimensionados, uma vez que o licenciamento ambiental continuou apesar das manifestações do Instituto Brasileiro do Meio Ambiente e dos Recursos Naturais Renováveis (Ibama), MPF, Tribunal de Contas da União (TCU) e de as condicionantes do próprio licenciamento não terem sido cumpridas (FAINGUELERNT, 2016).

A exploração dos recursos hídricos por meio da execução das obras da UHBM foi um dos principais alicerces da agenda de desenvolvimento do governo, a qual tem como pano de fundo o discurso da sustentabilidade:

"A sociedade brasileira está certa de que é necessário garantir energia elétrica para o crescimento do país e que isso deve ser feito mantendo nossa matriz energética limpa e renovável por meio de hidrelétricas" (PAC, 2014b).

"Agora é possível caminhar em direção a um crescimento mais acelerado e de forma sustentável, uma vez que a economia brasileira tem grande potencial de expansão. E tal desenvolvimento econômico deve beneficiar a todos os brasileiros e brasileiras e respeitar o meio ambiente" (PAC, 2014a).

"Quando entrar em operação em 2015, contribuirá com a geração de energia necessária para o Brasil continuar seu ciclo de desenvolvimento sustentável" (PAC, 2014b).

Teixeira (2007) pontua que

as ações do PAC não apontam para uma desejada transição para uma nova base técnica da economia e para um padrão de consumo diverso do tradicional, que impliquem em tensões na demanda por recursos naturais compatíveis com os limites da sustentabilidade, nos seus termos mais substantivos [...]. Preocupações com o meio ambiente não ultrapassam as finalidades dos discursos politicamente 
corretos, têm alimentado a constituição de um perigoso senso comum que julga as salvaguardas ambientais na atividade econômica como conspiratórias ao nosso "direito ao desenvolvimento" (p. 2).

Nesse contexto, apesar de o Direito ao Ambiente equilibrado ser classicamente classificado como difuso e coletivo, sua tutela deve ser entendida "dentro do marco teórico dos direitos sociais" (MACEDO JÚNIOR, 2013, p. 13), pois têm "o intuito de assegurar uma compensação pelas desigualdades fáticas entre as pessoas mediante a garantia de determinadas prestações por parte do Estado ou da sociedade" (DIMOULIS, 2007, p. 132), exigindo atuação estatal para a sua efetividade. Segundo Macedo Júnior (2013), tratam-se de:

1) direitos das desigualdades, pois socializam o risco e as perdas sociais, considerando grupos a serem protegidos de forma diferenciada, direcionando aos mais vulneráveis as políticas públicas, como idealmente seria a confecção de políticas públicas para os ribeirinhos e indígenas de Belo Monte atingidos pelos efeitos das barragens;

2) garantias de categorias ou grupos sociais que legitimam políticas públicas e tornam-se instrumento de governo e administração, fixados mediante normas jurídicas obrigando a sua proteção pelo Estado, que passa a estar vinculado a essas prestações, diminuindo sua discricionariedade;

3) direitos essencialmente contraditórios e polêmicos, pois integram um regime de normalidade provisória e flexível, que discutem as opções de direcionamento das dotações orçamentárias estatais e as necessidades dos grupos vulneráveis e outros interesses, como da iniciativa privada, uma vez que todos disputam os recursos limitados do Estado;

4) direitos dimensionados politicamente, pois permitem priorizar ações assecuratórias em conformidade com a realidade de cada local. A situação específica de Belo Monte e as alterações no ambiente e na sociedade locais implicam uma reavaliação das prioridades e a verificação das vulnerabilidades existentes anteriormente às obras da usina (que se mantiveram) e das novas vulnerabilidades decorrentes da UHBM.

De uma forma ou de outra, o licenciamento ambiental da UHBM atingiu direitos das populações tradicionais atingidas, sendo necessário, após a operacionalização da Usina, a busca de soluções no sentido de mitigar os impactos sociais e ambientais para "reverter a situação caótica da cidade de Altamira, que encontra-se, após um processo de aumento populacional e deslocamentos compulsórios, com maiores índices de criminalidade, prostituição e condições precárias de saúde" (FAINGUELERNT, 2016, p. 254).

Os grandes empreendimentos hidrelétricos devem considerar: as questões sociais e ambientais, associando crescimento ao desenvolvimento, uma concepção menos autoritária e mais democrática de sociedade e uma forma mais adequada de dimensionamento das soluções energéticas e das políticas públicas a ela vinculadas (FAINGUELERNT, 2016).

A UHBM, no PAC, seguiu o curso de uma agenda desenvolvimentista econômica nada transformadora, que caminhou na direção contrária da agenda ambiental, ou, ainda, nas palavras de Leff (2001, p. 69), baseia-se em um "processo de apropriação destrutiva [da natureza], gerada por uma racionalidade produtiva antinatural". 
Assim, os compromissos desenvolvimentistas, por meio de geração de empregos e melhorias de serviços públicos, transformaram-se em promessas para a região de Belo Monte e trouxeram consigo diversos impactos socioambientais. $O$ empreendimento aumentou o custo de vida dos moradores, agravou problemas de habitação, água, saneamento e diminuiu a produção de alimentos e de pesca na região (FEARNSIDE, 2002, 2006, 2015). O aumento da população durante as construções gerou especulação imobiliária e alterou a organização espacial urbana, a qual foi intensificada pelo deslocamento das populações em razão do aumento do nível da água em virtude da barragem (MORAN, 2016). A usina trouxe desmatamento, mudança na vazão dos corpos d'água, tanto a montante quanto a jusante, resultando em desequilíbrios ecossistêmicos (JIANG et al., 2018).

No caso de Belo Monte, a falta de informações, impossibilidade de alternativa à indenização, falhas para cadastro socioeconômico e a impossibilidade de manutenção das condições tradicionais de vida, são as principais reclamações judicializadas pela Defensoria Pública em Altamira, isso em decorrência de várias violações, como:

(i) as decisões sobre deslocamento são tomadas sem consulta, participação e informação da população deslocada; (ii) há desagregação familiar, rompimento de laços de vizinhança e de tradições culturais; (iii) usa-se de ameaças contra dos deslocados para a assinatura de acordos; (iv) há diversas consequências negativas do deslocamento como interrupção de tratamento médico, perda do emprego e de acesso a serviços básicos etc. (SCABIN et al., 2017, p. 22).

Os benefícios foram a pavimentação de trecho da Transamazônica e a criação de empregos, apesar de temporária (MORAN, 2019).

\section{CONSIDERAÇÕES FINAIS}

Toda esta agenda de cunho desenvolvimentista pode remeter a certa semelhança à ideologia nacionalista disseminada, por exemplo na Era Vargas, no governo JK e ao longo da ditatura militar. Naqueles períodos, o desenvolvimento apoiava-se em obras de infraestrutura, em investimentos na indústria de base e nos setores energético e de transportes de cada região brasileira, posto que a utilização dos recursos naturais deveria ser ampliada por meio do uso de técnicas modernas, afastado de sua dimensão social absolutamente necessária.

O desenvolvimento demanda, contudo, a reorientação do formato de acumulação do Brasil, que deve estar associado à produtividade social, legitimadora de um projeto nacional. Assim, a superação do subdesenvolvimento é pauta política e depende de um projeto social subjacente, permitindo a transformação do crescimento em desenvolvimento.

Belo Monte no PAC foi transformada no símbolo de desenvolvimento brasileiro, o qual se tornou (1) uma bandeira do Estado; (2) visto como multiplicador de investimentos e serviços em áreas prioritariamente relacionadas à infraestrutura; (3) capaz de sanar todas as deficiências econômicas e sociais, muito embora não focalize nos segmentos de educação e saúde; e (4) faz da apropriação da natureza (recursos hídricos) um dos pilares de sua agenda. 
Mesmo com as transições de gestão federal do Brasil, o PAC é um programa ativo. Seu discurso não foi modificado desde a sua criação e continua disponível no site do Estado. Há, portanto, a possibilidade de os mecanismos comunicacionais aqui discutidos serem reapropriados pelo próprio governo vigente ou demais atores, para justificar novas obras do mesmo segmento de Belo Monte, por exemplo, inclusive, na própria Amazônia, local de grande especulação hidrelétrica. Isso pode perpetuar enunciados parciais que não contemplam a complexidade social, econômica e ambiental dos empreendimentos propostos.

\section{AGRADECIMENTO}

Ao Cristiano Reis (Esalq/USP), pela colaboração no trabalho de geoprocessamento.

\section{REFERÊNCIAS}

ALEXANDER, J. E.; TATE, M. A. Checklist for an informational web page. 2000. Disponível em: https:// www.science.widener.edu/ withers/inform.htm. Acesso em: fev. 2020.

BNDES. Banco Nacional de Desenvolvimento Econômico e Social. Relatório de Investimentos do BNDES. 2011. Disponível em: http://www.bndes.gov.br/SiteBNDES/export/sites/default/bndes_pt/Galerias/Arquivos/conhecimento/relatorio_investimentos/relatorio_investimento042011.pdf. Acesso em: jan. 2020. BNDES. Banco Nacional de Desenvolvimento Econômico e Social. Relatório Anual 2012. 2012. Disponível em: http://www.bndes.gov.br/SiteBNDES/export/sites/default/bndes_pt/Galerias/Arquivos/empresa/ RelAnual/ra2012/relatorio_anual2012.pdf. Acesso em: jan. 2020.

BERMANN, C. O projeto da usina hidrelétrica Belo Monte: a autocracia energética como paradigma. Novos Cadernos NAEA, Belém, 15(1), p. 5-25, 2012.

BONAVIDES, P. Do Estado Liberal ao Estado Social. São Paulo: Malheiros, 2010.

BRANDÃO, C. Prefácio. In: D’AGUIAR, R. F. Essencial Celso Furtado. São Paulo: Penguin; Companhia das Letras, 2013. p. 11-16.

BRASIL. Dívida pública federal: relatório anual 2011. Brasília: Tesouro Nacional, 2012.

BUCCI, M. P. D. O conceito de políticas públicas em direito. In: BUCCI, M. P. D. Políticas públicas: reflexões sobre o conceito jurídico. São Paulo: Editora Saraiva, 2006. p. 1-50.

BUCCI, M. P. D. Fundamentos para uma Teoria Jurídica das Políticas Públicas. São Paulo: Saraiva, 2013.

BURSZTYN, M.; ASSUNÇÃO, F. N. Amazônia: cenas e cenários. Brasília: Editora UnB, 2004.

CABRERA, A. P. Presentación. In: SACHS, W. Diccionario del Desarrollo. New Jersey: Zed Books, 1996. p. 1-7.

CASTORIADIS, C. As encruzilhadas do Labirinto II. São Paulo: Paz e Terra, 1987.

DIMOULIS, D. Dicionário brasileiro de Direito Constitucional. São Paulo: Saraiva, 2007.

DINIZ, E. É possível um novo modelo de estado desenvolvimentista no Brasil? In: INSTITUTO DE PESQUISA ECONÔMICA APLICADA. Boletim de Análise Político-Institucional. Brasília: Ipea, 2011. p. 17-24.

DUARTE, C. S. O ciclo das políticas públicas. In: SMANIO, G. P.; BERTOLIN, P. T. M.; BRASIL, P. C. O Direito e as Políticas Públicas no Brasil. São Paulo: Atlas, 2013. p. 16-43.

FAINGUELERNT, M. B. A trajetória histórica do processo de licenciamento ambiental da usina hidrelétrica de Belo Monte. Ambiente e Sociedade, 19 (2), p. 245-264, 2016.

FAIRCLOUGH. N. Media discourse. London: Longman, 2001.

FAIRCLOUGH. N. Discurso e mudança social. Brasília: UNB, 2008.

FEARNSIDE, P. Avança Brasil: environmental and social consequences of Brazil's planned infrastructure in Amazonia. Environmental Management, 30(6), p. 735-747, 2002.

FEARNSIDE, P. Dams in the Amazon: Belo Monte and Brazil's hydroelectric development of the Xingu river basin. Environmental Management, 38(1), p. 16-27, 2006.

FEARNSIDE, P. Hidrelétricas na Amazônia: impactos ambientais e sociais na tomada de decisões sobre grandes obras. Manaus: Inpa, 2015. 
FGV. Fundação Getulio Vargas. O direito à proteção integral das crianças e dos adolescentes no contexto dos grandes empreendimentos: papéis e responsabilidades das empresas. São Paulo: Fundação Getúlio Vargas, 2013.

FGV. Fundação Getúlio Vargas. Programa de Aceleração do Crescimento. 2020. Disponível em: http:// www.fgv.br/cpdoc/acervo/dicionarios/verbete-tematico/programa-de-aceleracao-do-crescimento-pac. Acesso em: fev. 2020.

FURTADO, C. Desenvolvimento e subdesenvolvimento. Rio de Janeiro: Fundo de Cultura. 1961.

FURTADO, C. Comissão Econômica para a América Latina. In: D’AGUIAR, R. F. Essencial Celso Furtado. São Paulo: Penguin; Companhia das Letras, 2013a. p. 42-52.

FURTADO, C. Entre inconformismo e reformismo. In: D'AGUIAR, R. F. Essencial Celso Furtado. São Paulo: Penguin; Companhia das Letras, 2013b. p. 27-41.

FURTADO, C. O mito do desenvolvimento econômico. In: D’AGUIAR, R. F. Essencial Celso Furtado. São Paulo: Penguin; Companhia das Letras, 2013c. p. 82-85.

FURTADO, C. O verdadeiro desenvolvimento. In: D’AGUIAR, R. F. Essencial Celso Furtado. São Paulo: Penguin; Companhia das Letras, 2013d. p. 53.

HOUAISS. Dicionário Houaiss da língua portuguesa. Rio de Janeiro: Objetiva, 2009.

IBGE, Instituto Brasileiro de Geografia e Estatística. Estatísticas Sociais, 2020. Disponível em: https://agenciadenoticias.ibge.gov.br/agencia-sala-de-imprensa/2013-agencia-de-noticias/releases/27515-pnad-continua-tic-2018-internet-chega-a-79-1-dos-domicilios-do-pais. Acesso em: fev. 2020.

GOMIDE, A. A.; PIRES, R. R. C. Capacidades estatais para o desenvolvimento no século XXI. In: INSTITUTO DE PESQUISA ECONÔMICA APLICADA - IPEA. Boletim de Análise Político-Institucional. Brasília: Ipea, 2011. p. 25-30.

GREENPEACE. Hidrelétricas na Amazônia. 2018. Disponível em: https://storage.googleapis.com/planet4-brasil-stateless/2018/07/relatorio_hidreletricas_na_amazonia.pdf. Acesso em: fev. 2020.

HERMAN, E. S.; CHOMSKY, N. A manipulação do público: política e poder econômico no uso da mídia. São Paulo: Futura, 2003.

HOCHSTETLER, K. The politics of environmental licensing: energy projects of the past and future in Brazil. Studies in Comparative International Development, v. 46, n. 4, p. 349-371, 2011.

JARDIM, M. C.; SILVA, M. R. Programa de Aceleração do Crescimento (PAC): neodesenvolvimentismo? São Paulo: Unesp, 2015.

JIANG, X. et al. Examining impacts of the Belo Monte hydroelectric dam construction on land-cover changes using multitemporal Landsat imagery. Applied Geography, v. 97, p. 35-47, 2018.

KHAGRAM, S. Dams and developments: Transnational struggles for water and power. Ithaca, NY: Cornell University Press, 2004.

KUGELMAS, E. Revisitando o desenvolvimento. Revista Brasileira de Ciências Sociais, São Paulo, v. 22, n. 63, p. 6-10, 2007. Disponível em: https://www.scielo.br/pdf/rbcsoc/v22n63/a02v2263.pdf.

LASSANCE, A. Agenda política, mudanças institucionais e perspectivas futuras: questões centrais para o ano de 2012. In: IPEA. Instituto de Pesquisa Econômica Aplicada. Boletim de Análise Político-Institucional. Brasília: Ipea, 2011. p. 9-16.

LEFF, E. Saber ambiental: sustentabilidade, racionalidade, complexidade e poder. Rio de Janeiro: Vozes, 2001.

MACEDO JÚNIOR, R. P. Direito social, o meio ambiente e o desenvolvimento: reflexões em torno de um caso de sucesso. Revista de Direito Ambiental, São Paulo, 18(70), p. 13-35, 2013.

MARTIN, J. R.; WHITE, P. R. R. The language of evaluation: appraisal in English. New York: Palgrave, 2005. MME. Ministério de Minas e Energia Belo Monte. 2011. Disponível em: http://www.mme.gov.br/mme/ menu/belo_monte.html. Acesso em: jan. 2020.

MINISTÉRIO PÚBLICO fEDERAL. Procuradoria da República do Pará. Processos caso Belo Monte. 2020. Disponível em: http://www.mpf.mp.br/regiao1/sala-de-imprensa/docs/tabela-belo-monte. Acesso em: 15 set. 2020.

MORAN, E. F. Roads and dams: infrastructure-driven transformations in the Brazilian Amazon. Ambiente $e$ Sociedade, Campinas, 19(2), p. 207-220, 2016.

MORAN, E. F. Belo Monte descumpriu promessa de levar desenvolvimento sustentável à região amazônica. 2019. Disponível em: http://agencia.fapesp.br/belo-monte-descumpriu-promessa-de-levar-desenvolvimento-sustentavel-a-regiao-amazonica/31374/. Acesso em: maio 2020.

MXVPS. Movimento Xingu Vivo Para Sempre. Histórico. 2010. Disponível em: http://www.xinguvivo.org. br/2010/10/14/historico/. Acesso em: jan. 2020. 
NORTE ENERGIA. UHE Belo Monte. 2014. Disponível em: https://www.norteenergiasa.com.br/pt-br/uhe-belo-monte/a-usina. Acesso em: jan. 2020.

OLIVEIRA, F. A era da indeterminação. São Paulo: Boitempo, 2007.

PAC. Programa de Aceleração do Crescimento. Dez maiores obras-PAC. 2013. Disponível em: http://www. pac.gov.br/i/f1e1c8ab. Acesso em: jan. 2020.

PAC. Programa de Aceleração do Crescimento. Sobre o PAC. 2014a. Disponível em: http://pac.gov.br/sobre-o-pac/medidas. Acesso em: jan. 2020.

PAC. Programa de Aceleração do Crescimento. Belo Monte: desenvolvimento com sustentabilidade. 2014b. Disponível em: http://pac.gov.br/noticia/96d1096a. Acesso em: jan. 2020.

PAC. Programa de Aceleração do Crescimento. Belo Monte, antes e depois. 2014c. Disponível em: http:// pac.gov.br/noticia/0132dfd8. Acesso em: jan. 2020.

PAC. Programa de Aceleração do Crescimento. Visão Geral. 2014d. Disponível em: http://www.planejamento.gov.br/includes/faq/faq.asp?sub=1. Acesso em: jan. 2020.

PEDROSA, C. E. F. Análise crítica do discurso: do linguístico ao social no gênero midiático. Aracaju: Editora UFS, 2008.

PEREIRA, K. A. Desenvolvimentismo, conflito e conciliação de interesses na política de construção de hidrelétricas na Amazônia brasileira. Brasília: Ipea, 2013.

PNE. Plano Nacional de Energia. Plano Nacional de Energia 2030. 2007. Disponível em: http://www.epe. gov.br/PNE/20080512_3.pdf. Acesso em: jul. 2014.

RAMOS, A. M.; ALVES, H. P. F. Conflito socioeconômico e ambiental ao redor da construção da Usina Hidrelétrica Belo Monte. Desenvolvimento e Meio Ambiente, 46, p. 174-196, 2018.

ROMANO, S. O ordenamento jurídico. Florianópolis: Fundação Boiteux, 2008.

SAMPAIO JÚNIOR, P. A. PAC: nem crescimento nem igualdade. 2007. Disponível em: http://antigo.mst. org.br/jornal/270/artigo. Acesso em: jan. 2020.

SANTOS, C. et al. PAC: uma orientação neoliberal para as políticas sociais - gestão dos direitos ou dos negócios do social? Ser Social, Brasília, 12(26), p. 116-146, 2010.

SCABIN, F. S.; CRUZ, J. C. C.; HOJAIJ, T. B. Processos de auditoria em direitos humanos e mecanismos de participação: lições e desafios advindos do licenciamento ambiental brasileiro. Aracê - Direitos Humanos em Revista, a. 2, n. 3, p. 162-179, set. 2015. Disponível em: https://arace.emnuvens.com.br/arace/article/ view/58. Acesso em: 15 set. 2020.

SCABIN, F. S. et al. A violação de direitos dos ribeirinhos no contexto Belo Monte e os processos de assistência jurídica na DPU, em Altamira. In: MAGALHÃES, S. B.; CUNHA, M. C. A expulsão de ribeirinhos em Belo Monte: Relatório da SBPC. Capítulo 8. 2017. Disponível em: http://portal.sbpcnet.org.br/livro/belomonte.pdf. Acesso em: 15 set. 2020.

SCHMITZ, A. A. Fontes de notícias: ações e estratégicas das fontes no jornalismo. Florianópolis: Combook, 2011.

SICSÚ, J. Após 4 anos, governo tenta mudar o rumo. 2007. Disponível em: http://www.cartamaior.com. br/?/Editoria/Economia/Apos-4-anos-governo-tenta-mudar-o-rumo/7/12590. Acesso em: jan. 2020.

SILVA, V. A. Direitos fundamentais: conteúdo essencial, restrições e eficácia. São Paulo: Malheiros, 2009. SUNKEL, L. O.; PAZ, P. El sudesarrollo latinoamericano y la teoría del desarrollo. México: Siglo XX Editores, 1988.

TEIXEIRA, G. O Programa de Aceleração do Crescimento e o Meio Ambiente. 2007. Disponível em: http:// www.fase.org.br/v2/admin/anexos/acervo/17_070316_artigo_pac_gerson_teixeira.pdf. Acesso em: jan. 2020. 